\title{
Microstructure, texture and mechanical behavior characterization of hot forged cast ZK60 magnesium alloy
}

\author{
S.M.H. Karparvarfard ${ }^{1}$, S.K. Shaha ${ }^{1}$, S.B. Behravesh ${ }^{1}$, H. Jahed ${ }^{1, *}$, B.W. Williams ${ }^{2}$ \\ ${ }^{1}$ Department of Mechanical \& Mechatronics Engineering, University of Waterloo, \\ 200 University Ave W, Waterloo, ON N2L 3G1, Canada \\ ${ }^{2}$ CanmetMATERIALS, Natural Resources Canada, 183 Longwood Road South, Hamilton, \\ ON L8P 0A1, Canada
}

Corresponding author.

E-mail address: skumarsh@uwaterloo.ca (Sugrib Kumar Shaha); hjahedmotlagh@uwaterloo.ca (Hamid Jahed)

[Received 22 October 2016; Received in revised form 31 January 2017; Accepted 31 January 2017]

\begin{abstract}
Uniaxial tension and compression tests were conducted to investigate the quasi-static performance of ZK60 Mg alloy in cast, followed by forging at optimum temperature of $450{ }^{\circ} \mathrm{C}$ and a ram speed of $39 \mathrm{~mm} \mathrm{~min}^{-1}$ condition. Microstructure and texture analysis showed that the as-cast alloy exhibited a dendritic structure with casting porosity and random texture. In contrast, the forged alloy exhibited a refined grain structure with a significant reduction in casting porosity, while the texture changed to sharp basal texture. Measured mechanical properties of the forged alloy showed that the strength did not change, however, the ductility improved by $75 \%$. The analysis of the fracture surface of the forged alloy under tension revealed a ductile fracture
\end{abstract}


with dimple morphology, while the as-cast alloy displayed a brittle fracture with open pores. This demonstrated that the reduction of casting defects and dendritic morphology, as well as the evolution of recrystallized grains, enhanced the ductility, while partial dynamic recrystallization through the forging process resulted in only marginal modification of strength in the forged condition.

Keywords: Magnesium; Forging; Ductility; Texture; Recrystallization

\section{Introduction}

Concerns over the environmental impacts of fossil fuels have led to the development of aggressive fuel efficiency targets. An effective way to increase fuel efficiency is to decrease vehicle weight by utilizing lightweight metallic materials like magnesium $(\mathrm{Mg})$ and its alloys, which have superb specific strength, good cast-ability, and excellent damping capacity [1-3]. To date, the use of $\mathrm{Mg}$ for automotive applications has mainly been limited to trimming and nonstructural members. Expanding the use of $\mathrm{Mg}$ to load-bearing components with complex shapes requires a thorough understanding of $\mathrm{Mg}$ behaviour after manufacturing.

Magnesium has a hexagonal closed-pack (hcp) crystal structure with $c / a<\sqrt{3}$, which translates to limited formability at lower temperatures, preventing its widespread use for industrial applications. According to the von Mises criterion, five independent deformation modes are required to accommodate induced strains during homogenous deformation for a polycrystalline material. At lower temperatures, basal, prismatic, and pyramidal slip planes are active, but the lower strength required for basal slip will result in the formation of a strong basal 
texture during deformation $[4,5]$. If basal slip is hindered, twinning systems can be activated at lower temperature. Additional slip systems are activated at elevated temperatures, which improves formability, but lowers the strength of deformation [6,7].

The leading manufacturing process ( $90 \%)$ of $\mathrm{Mg}$ alloy parts is die casting. However, the occurrence of casting defects like porosities, dry oxides, and inclusions, limits the alloy strength and thus the suitability of $\mathrm{Mg}$ alloys in the as-cast state for industrial applications [8]. Studies have shown that $\mathrm{Mg}$ alloys in wrought conditions exhibit refined grains $[9,10]$, better tensile properties like strength and deformability [11,12], improved fracture toughness [12], and longer fatigue life [13,14], which expand the opportunities for use of Mg alloys as structural materials. Extrusion, which forms strong basal texture and bimodal grains, is a common material processing technique for wrought Mg alloys [12-18]. Recently, equal channel angular pressing (ECAP), which causes severe plastic deformation (SPD), has been employed for processing $\mathrm{Mg}$ alloys. ECAP refines the microstructures and weakens the texture of the Mg alloys $[19,20]$. However, these processes cannot be used for manufacturing complex parts. Forging is an efficient technique, in which the structural parts are produced in a near net shape [21]. Because of its promise as an effective manufacturing method for $\mathrm{Mg}$ alloy microstructure refinement and mechanical property improvement, forging is currently of significant interest for industrial applications [22,23].

In general, the Mg ZK series, and ZK60 in particular, have good formability [24,25]. They also have good strength due to precipitations and grain refining effects of $\operatorname{Zr}$ [26,27]. ZK60 is the forged alloy among others forgeable $\mathrm{Mg}$ alloys. The effects of microstructure and texture on the mechanical properties of extruded, rolled, and ECAP ZK60 have been reported extensively in the literature [11,28-30]. Findings of these studies demonstrate that the mechanical properties, 
especially the ductility, which controls the formability of the ZK60 Mg alloy, improved significantly as a result of the presence of fine grain structures and the modified texture of as-cast materials. The texture evolution of as-extruded ZK60 following equal channel angular extrusion (ECAE) has been studied by Agnew et al. [31]. They observed that while AZ-series Mg alloys pretend to accommodate both $\langle a\rangle$ and $\langle c+a\rangle$ non-basal slips, ZK-series Mg alloys prefer nonbasal $\langle c+a\rangle$ slip systems. Multi steps processing (MSP) or Multi directional forging (MDF) is becoming a popular material processing technique to enhance the mechanical properties of $\mathrm{Mg}$ alloys. The MDF or MSP has been employed on Mg alloys after casting, extrusion, and rolling for refining the microstructure and texture, which leads to improved tensile and fatigue properties. Wu et al. [32] studied the effect of high strain rate multiple forging (HSRMF) on commercial semi-continuous casting ZK60 Mg alloy. They reported that during MDF, twins are induced, and rotational dynamic recrystallization occurs, which forms honeycomb-like coarse and island-like ultrafine dynamic recrystallized (DRX) grains, resulting in improved ductility and tensile strength. Other studies on MDF of ZK60 Mg alloys in extruded condition demonstrated the formation of a bimodal microstructure containing about $80 \%$ recrystallized fine grains (3-6 $\mu \mathrm{m})$ with elongated grains ( 1 mm long and $\sim 50 \mu \mathrm{m}$ thick) [33], which significantly improved the ductility and tensile strength [34], leading to the improvement of low cycle and high cycle fatigue properties $[35,36]$. More recently, researchers reported achieving superior ductility and strength enhancement of ZK60 Mg alloy sheets by a combination of repeated upsetting and forward extrusion [37]. Accordingly, most of the machine parts in manufacturing industries are forged in one pass instead of multiple passes. However, forging as a manufacturing technique has received less attention than other techniques such as die casting, rolling, and extrusion. Ogawa et al. [38] investigated the appropriate temperature range for precision forging of ZK60, 
through the upset-ability test and backward extrusion. They reported that at forming temperatures below $200{ }^{\circ} \mathrm{C}$, cracks occurred, resulting in a height reduction of $39 \%$ during the upset-ability test. At deforming temperatures between $250{ }^{\circ} \mathrm{C}$ and $400{ }^{\circ} \mathrm{C}$, the $\mathrm{Mg}$ billet had excellent workability and backward extrusion capability. It was also observed that deformation temperatures should not exceed $400{ }^{\circ} \mathrm{C}$ to avoid severe oxidation, which significantly increases friction. Matsumoto and Osakada [39] suggested keeping the billet in a non-oxidizing atmosphere, or riding off the oxide by applying lubricant on the tools and billet to reduce friction during forging at temperatures of $200-400{ }^{\circ} \mathrm{C}$ [40]. Kwon et al. [41] investigated the forgeability of $\mathrm{Mg}$ alloys in terms of forging temperature, speed, and grain size. They demonstrated that forging speed is more sensitive than temperature, and finer grains are required for the successful forging of Mg alloys. Researchers have also demonstrated that the tensile strength of forged ZK60 decreased with increasing forging temperature, while the elongation increased significantly $[42,36]$ with temperature. However, most of the data presented in the literature are focused on the microstructural studies, followed by the tensile properties of the forged $\mathrm{Mg}$ alloys, while less attention has been devoted to the compression behavior of the cast and forged conditions. Moreover, the effect of tensile and/or compressive loading on the microstructure and texture of as-cast and forged ZK60 Mg alloys has not been comprehensively investigated.

The objective of this research was to characterize the microstructure, texture, and mechanical behavior of as-cast ZK60 before and after hot forging. Toward this goal, monotonic tension and compression tests were carried out before and after forging, and the microstructure and texture were examined before and after mechanical tests of both as-cast and forged ZK60 Mg alloy.

\section{Experimental}




\subsection{Forging of ZK60 Mg alloy}

The starting material used in this investigation was a commercial ZK60 Mg alloy cast ingot (chemical composition is presented in Table 1), with a diameter of $300 \mathrm{~mm}$ and a length of 500 $\mathrm{mm}$. The ingot was machined to a diameter of $63.5 \mathrm{~mm}$ and a length of $200 \mathrm{~mm}$. Finally, each piece was cut into three billets, each with a length of $65 \mathrm{~mm}$, for the forging. The as-cast ZK60 Mg alloy billet was heated over $3.5 \mathrm{~h}$ in an oven at two different temperatures of $350{ }^{\circ} \mathrm{C}$ and 450 ${ }^{\circ} \mathrm{C}$, then transferred to the forging anvil, which was also heated at the same temperatures. The upsetting was performed along the radial direction at a ram speed of $39 \mathrm{~mm} \mathrm{~min}^{-1}$. To reduce the friction between the materials and the platform, a graphite lubricant was used, which also acted as a protective layer to prevent oxidation. Fig. 1 shows the forged samples at different temperatures. A significant number of edge cracks were observed in the samples deformed at $350{ }^{\circ} \mathrm{C}$, while the samples deformed at $450{ }^{\circ} \mathrm{C}$ were crack-free, with no prominent oxidation. An $80 \%$ height reduction was accommodated in the forging process. The lowest melting point of the eutectic phase for ZK60 Mg alloy has been reported to be $339.5^{\circ} \mathrm{C}$ [43]. The volume fraction of the eutectic phase was below 3\%, which was estimated using "Factsage" software. It was therefore expected that during slow heating of the billet up to $450{ }^{\circ} \mathrm{C}$ for $3.5 \mathrm{~h}$, the eutectic phase would be dissolved into the $\mathrm{Mg}$ matrix, which could have led to a better forging response of ZK60 at $450{ }^{\circ} \mathrm{C}$. Also, a recent study by Hadadzadeh et al. [44] on the same ZK60 cast alloy using a Gleeble ${ }^{\circledR} 3500$ thermal-mechanical simulation testing system reported no incipient melting in the microstructures. Thus, the sample deformed at $450{ }^{\circ} \mathrm{C}$ was selected for further testing in this study. 


\subsection{Microstructure and texture analysis}

For microstructure and texture analysis, the samples were collected from the as-cast billet and forged parts. To ensure consistency, all the test samples of the as-cast billet were collected at a distance equivalent to $75 \%$ of the billet radius, and all the forged test samples were extracted from the middle portion of the forged part, away from the curved edges. The samples for microstructural and texture analyses were prepared using up to 1200-grit SiC sand paper. After that, the samples were polished with $6,3,1$, and $0.1-\mu \mathrm{m}$ diamond paste with oil based lubricant on the imperial cloth. Finally, the samples were polished using colloidal silica on the black CHEM pad. An etchant with a chemical composition of $4.2 \mathrm{~g}$ picric acid, $70 \mathrm{ml}$ ethanol, $10 \mathrm{ml}$ acetic acid, and $10 \mathrm{ml}$ distilled water was used to etch the sample. The microstructure was examined in unetched and etched conditions using an optical microscope (OM) and a scanning electron microscope (SEM), coupled with energy-dispersive X-ray spectroscopy (EDX). The phases present in the as-cast alloy were identified using Bruker D8-discover equipped with advanced 2D-detector and $\mathrm{Cu} K_{\alpha 1}$ radiation of X-ray diffractometer (XRD). To collect the diffraction patterns, the following parameters were used: accelerating voltage of $40 \mathrm{kV}$, current of $40 \mathrm{~mA}$, step size of $15^{\circ}$, and scanned speed of $60 \mathrm{~s}$ for each step of the $2 \theta$ angle, from $25^{\circ}$ $95^{\circ}$. The collected diffraction patterns were evaluated using Bruker trademark software "DIFFRAC.EVA".

Texture measurements before and after forging tests were performed using the same XRD machine on polished samples. The experiment was conducted by measuring the incomplete pole figures (PFs) of $\{0001\},\{10 \overline{10}\},\{10 \overline{1} 1\}$, and $\{1 \overline{1} 02\}$ for tilt angle $(\Psi)$ between $0^{\circ}$ and $75^{\circ}$, and 
in axis rotation $(\Phi)$ from $0^{\circ}$ to $360^{\circ}$ in the back-reflection mode. Finally, the complete PFs were calculated based on the measured incomplete PFs using DIFFRAC.Suite: Texture software.

\subsection{Tension and compression properties}

As illustrated in Fig. 2(a), dog-bone flat samples for tension and cubic samples for compression tests were extracted from as-cast material along the radial (RD) and longitudinal (LD) directions. Similar types of samples were cut from the forged material along different orientations, and were labeled as shown in Fig. 2(b). However, the compression test on the forged material was performed in $\mathrm{LD}, \mathrm{RD}$, and forging direction (FD). The dimensions of the tension and compression tests samples are given in Fig. 3 and Table 4.

All monotonic tension tests were performed under standard laboratory conditions in displacement controlled mode using an Instron 8874 servo-hydraulic frame having a capacity of $\pm 25 \mathrm{kN}$. Compression tests were also performed at room temperature in the same controlling mode as tension testing-utilizing MTS 810 machine, with a load capacity of $\pm 50 \mathrm{kN}$. The crosshead speed for both the tension and compression tests was $1 \mathrm{~mm} \mathrm{~min}^{-1}$. Strain measurement for the tension specimens was performed using an extensometer with a gage length of $10 \mathrm{~mm}$ and $\pm 1.5 \mathrm{~mm}$ travel limits. For compression tests, strain was measured using the ARAMIS 3D Digital Image Correlation (DIC) system with 5 megapixel resolution and a frame rate of $15 \mathrm{fps}$. After testing, the fracture surfaces were examined by SEM. At least two samples were tested for each testing condition. Samples were also cut and polished along the loading axis to observe the microstructure and texture near the fracture surfaces. 


\section{Results}

\subsection{Microstructure}

Typical OM and SEM microstructures of the as-cast ZK60 Mg alloy in the unetched and etched conditions are shown in Fig. 4. The presence of alloying elements in the intermetallics of the alloy is identified using an EDX line scan (Fig. 4d and e). As seen in Fig. 4a, the microstructure exhibits casting porosities with intermetallics. A secondary dendritic arm spacing (SDAS) of $(23.43 \pm 5.32) \mu \mathrm{m}$ and a grain size of $(131.44 \pm 25.84) \mu \mathrm{m}$ was observed in as-cast materials in the etched condition (Fig. $4 \mathrm{~b}$ and c). The EDX point analysis revealed that the alloy microstructure consisted of $\alpha-\mathrm{Mg}$ dendrites with two intermetallic phases: $\mathrm{MgZn}_{2}$ and $\mathrm{Zn}_{2} \mathrm{Zr}$. The presence of phases in the as-cast alloy was confirmed by XRD analysis, as illustrated in Fig. 5. These intermetallics were formed in the intergranular and interdendritic region during solidification of the alloy, as seen in Fig. 4c. Similar types of intermetallics have been reported in the literature for the ZK60 Mg-alloy [43].

The microstructural analysis was performed for the forged sample as well. A modified microstructure of the forged ZK60 Mg alloy is shown in Fig. 6. It can be seen that the porosity fraction has decreased significantly in the forged alloy (Fig. 6a). The forged microstructure in Fig. $6 \mathrm{~b}$ exhibits bimodal grain structure: elongated pancaked type grains surrounded by fine grains $(2-5 \mu \mathrm{m})$, which are more visible in the magnified image in Fig 6c. However, the dendritic marks (shown by the black arrow) are still visible. This could be due to incomplete DRX during forging at higher temperatures. It has been reported that the presence of the $\mathrm{Zr}$-rich phase in ZK60 Mg alloy causes a pinning effect, which hinders the movement of dislocations and prevents DRX, resulting in incomplete grain refinement [45]. Similar types of grain structures 
with incomplete DRX, and a similar pinning effect of Zr-rich precipitates during hot deformation of the ZK60 Mg alloy have been reported in Ref. [46,47].

\subsection{Texture analysis of cast and forged samples}

The as-cast ZK60 Mg alloy, shown in Fig. 7a, exhibited a random texture with a maximum intensity of 5.08 multiples of random distribution (MRD) in basal plane of (0002), while the prismatic $(10 \overline{1} 0)$ poles reach an intensity of 3.46 MRD. Although the PFs show a strong pole density in the as-cast materials, there was no preferred orientation that can be considered as texture in the materials; i.e., the hcp unit cells are randomly distributed in the materials, as shown schematically in Fig. 7a. In contrast, the forged materials obtained a strong basal texture with a maximum intensity of 5.70 and 2.21 MRD for the basal plane (0002) and the prismatic plane ( $10 \overline{1} 0$ ), respectively, depicted in Fig. $7 \mathrm{~b}$. As seen in the schematic illustration, the unit cells in the forged materials are aligned towards the FD and the $(10 \overline{1} 0)$ poles were observed towards $\mathrm{LD}$, indicating that the prismatic $(10 \overline{1} 0)$ plane of hcp unit cells in the grains were perpendicular

to the FD. As a result, a set of basal textures, i.e., $\{0001\}\langle 2 \overline{1} \overline{1} 0\rangle$ could be identified in the forged ZK60 Mg alloy.

\subsection{Monotonic tension test}

The engineering stress-strain plot obtained from the monotonic tension tests in the as-cast and forged conditions is shown in Fig. 8. The monotonic tension properties are listed in Table 2. The results of this study and of a similar upsetting Ref. [37] (also shown in Table 2) demonstrate that higher ductility is always achieved after forging, compared to the ductility of as-cast or asextruded materials. It is evident from Fig. 8 that the tensile behavior is very similar in RD and LD orientations for both as-cast and forged samples. Hence, the yield strengths in tension (YST) 
and ultimate tensile strengths (UTS) in LD and RD are almost the same. The average YST of the as-cast material was $140 \mathrm{MPa}$, and the average UTS was $278 \mathrm{MPa}$. The as-cast material achieved an average elongation of $\sim 15 \%$ along the $\mathrm{LD}$, and $\sim 14 \%$ along the $\mathrm{RD}$. In comparison, the yield strength and elongation of the forged alloy increased by $21 \%$ and $72 \%$, respectively. The YSTs of the forged alloy were $163 \mathrm{MPa}$ and $177 \mathrm{MPa}$ and the tensile fracture strain values were $26 \%$ and $24 \%$ in the LD and RD, respectively. However, the UTS after forging was approximately the same as that of the as-cast (285 MPa). The same behavior has also been reported in a study on the effects of warm rolling on the mechanical properties of ZK60 Mg alloy. The ultimate strengths along the rolling direction, $45^{\circ}$ to the rolling direction, and the direction perpendicular to rolling direction were the same, while yield strengths along these orientations were different from that in Ref. [48].

\subsection{Monotonic compression behavior}

The compression tests were conducted on the as-cast material in the two orthogonal directions of RD and $\mathrm{LD}$, and on the forged material along the RD, LD, and FD. Fig. 9 depicts typical engineering stress-strain curves of the as-cast and forged samples tested under compression. The compressive strains and stresses in this figure are reported in their absolute magnitudes. The monotonic compression properties along different directions are summarized in Table 3. The fracture strain and ultimate compressive strengths (UCS) of as-cast material were the same in the $\mathrm{LD}$ and $\mathrm{RD}$ directions ( $\sim 19 \%$ and $\sim 353 \mathrm{MPa}$, respectively). However, the materials achieved a yield strength in compression (YSC) of $109 \mathrm{MPa}$ along the LD, and 118 $\mathrm{MPa}$ along the RD. In comparison, the UCS of the forged alloy increased significantly at the expense of a reduction in fracture strain. The YSCs of the forged alloy were $127 \mathrm{MPa}, 119 \mathrm{MPa}$, and $111 \mathrm{MPa}$ along FD, RD, and LD directions, respectively, while the UCSs were $373 \mathrm{MPa}$, 
$391 \mathrm{MPa}$, and $390 \mathrm{MPa}$, respectively. The fracture strain was between $13 \%$ and $15 \%$ in all three directions. It is evident that the compression curves of the as-cast ZK60 material in LD and RD are similar to one another. This is in agreement with the texture measurement results. The basal and non-basal slip systems are dominant during compression of the as-cast material, but in the forged samples, particularly in the RD and LD directions, the stress-strain curves show that additional twinning systems are active and lead to deformation asymmetry.

Fig. 10 shows the compression engineering stress $v s$. engineering plastic strain curves of the as-cast materials exhibiting three prominent stages: elastic, plastic with decreasing hardening, and plastic with increasing hardening. The pure elastic behavior saturates at a stress value of 70 $\mathrm{MPa}$, which is lower than that of tension loading. Beyond that, at stress values above $113 \mathrm{MPa}$, yielding occurs and considerable strain hardening is seen (Fig. 10). The strain hardening rate during this stage is decreasing. In contrast, the anisotropic behavior of the forged ZK60 sample is obvious, which is due to the activation of twinning in two directions and idling of that when material is loaded along the FD. Indeed, the texture analysis reveals that the $c$-axes in hcp crystals are primarily orientated along the FD (Fig. 7b). This orientation favours triggering extension-twins $\langle 10 \overline{1} 2\rangle$ when the compression load is applied along a direction perpendicular to the $c$-axis of the hcp unit cell of the grains; i.e., RD and LD. Along RD and LD, when the stress exceeds $\sim 115 \mathrm{MPa}$, pronounced twinning starts and the curve ultimately becomes concave-up or sigmoidal in shape. As stress increases, non-basal slips can be activated in the twinned areas. Additionally, twin boundaries hinder dislocation movements; consequently, the rate of strain hardening increases. It was also observed that stress of approximately $300 \mathrm{MPa}$ causes twinning exhaustion. Under this amount of stress, tension twinning does not occur to a significant extent; as a result, the twinning boundary area is minimal and does not significantly obstruct the 
dislocation movement, which results in a decrease in the strain hardening rate. The cumulative effects of these competing factors: strain hardening due to twin boundaries, strain softening due to new twin formation, and the interaction between the twins and dislocation slips occurring during further compression, have previously been reported in Ref. [49,50]. It is also important to note that along the FD, yielding occurs at $\sim 127 \mathrm{MPa}$, accompanying a concave-down curve until fracture occurs. During this stage, non-basal slip is expected to be the principal deformation mode, and the rate of strain hardening decreases [51].

\subsection{Microstructure and texture after deformation of cast and forged samples}

Fig. 11 depicts the optical microstructures and the fracture profile, including the crack propagation in the as-cast and forged samples obtained from the tension tests along the LD. There are no visible twins observed in the micrograph. The multiple cracks with voids were formed in both as-cast and forged conditions. However, it is clear that the driving force for fracture in the as-cast sample was the normal stress, since it has failed in the plane of maximum normal stress (normal to uniaxial loading direction), while shear stress has driven a ductile fracture in the forged sample with the fracture plane angled about $45^{\circ}$ to the uniaxial tension loading. In the as-cast material, porosities and defects are the likely causes of the crack formation [52,53]. Fig. 11a exhibits a large secondary crack that has propagated across the grain boundaries (intergranular). This type of crack propagation is a manifestation of brittle fracture. A combination of twin grains and parent grains is evident in the as-cast sample deformed along the LD. In contrast, the microstructure of the sample compressed along the LD exhibits a significant trace of twining, while the sample compressed along the FD shows elongated deformed grains without twining. 
The change in texture during tension and compression, obtained from the samples after final fracture, is shown in Figs. 11 and 12. In the tensile test sample in the as-cast condition, the basal (0002) presented some concentration of the intensity toward the tensile direction. This means that the $c$-axes of hcp unit cells in some grains, which were favourable for twining, rotated along the loading direction. In contrast, in the forged samples, the maximum basal pole (0002) intensity was in the same orientation, which indicated that the orientation of the unit cell was not favourable for twining deformation. By contrast, the texture results obtained from compression samples show a significant change in orientation of the PFs. As seen in Fig 12(a), the maximum pole density of the as-cast sample was 8.29 MRD, which is parallel to the LD. This finding suggests that those unit cells were not aligned along the $\mathrm{CD}$, and that after compression all the unit cells in the grains were rotated and achieved a strong basal texture. In contrast, the forged sample compressed along the LD (Fig. 12b) obtained a texture intensity rotation of about $90^{\circ}$ (unit cells as shown schematically), while the maximum texture intensity of the (0002) pole remained in the same direction for the sample compressed along the FD (Fig. 12c). These texture results support the observed stress-strain behavior of the tested samples shown in Figs. 8 and 10, where the obtained compression curves in LD exhibit a sigmoidal shape, an indication of twining deformation.

\subsection{Fracture analysis}

The fractured surfaces obtained during tension testing of the as-cast and forged samples were also examined via SEM, and are illustrated in Fig. 13. As seen in Fig. 13a, the intergranular cracks, which are evidence of brittle fracture, are visible in the fracture surface of the as-cast ZK60, while fractographic analysis of the forged samples (Fig. 13c) demonstrates a ductile fracture. As seen in Fig. 13b, the magnified view of the fracture surface of as-cast materials 
shows large porosity surrounded by a tear ridge of the grains, which influences the alloy ductility. In contrast, there was no visible porosity present in the microstructure of the fracture surface of forged material shown in Fig. 13d. Instead, dimples with tear ridges, which indicates a ductile fracture, are identified. It is clear that the forged material has higher ductility compared to the as-cast material.

\section{Discussion}

The above results clearly indicate that the microstructure of as-cast ZK60 Mg alloy was refined by forging at elevated temperatures. The degree of modification in the microstructural features, such as dispersoid phases, grain size, and dendritic structures, is beneficial for the improvement of alloy performance in service. As seen in Fig. 8 and Table 2, the forging process contributes to a significant improvement in YST and ductility, while the UTS remains approximately the same between the as-cast and forged conditions. As discussed earlier, the improvement of alloy tensile properties, especially ductility, depends on the presence of defects in the alloy. Shaha et al. [52] reported that porosity play a significant role in cast alloys. They reported that during tension loading, pores tend to elongate, open, and increase in size, and therefore connect with one another more easily, which increases the potential for crack propagation. This in turn may result in premature fracture and affect the hardening and ductility of the alloy. As illustrated in Figs. 4 and 6, the as-cast alloy contains significantly more casting defects, such as pores, compared to the forged alloy, which eventually achieved better tensile ductility. Fractographic analysis also confirmed that the porosity severely affects the as-cast alloy ductility; this was also reported in a study on the effects of heat treatment on the forged Mg-Y-Zr alloy [54]. The authors analyzed the microstructure using X-ray computed tomography (XCT), and concluded that forging can significantly reduce casting porosity. Another potential 
reason for the lower ductility of the cast material is the presence of coarse intermetallics in the as-cast microstructure. The second phase particles, like intermetallics, also influence the alloy strength. The coarse intermetallics contain defects, which form voids during deformation. Those voids are interconnected with each other, leading to the final fracture of the cast alloy at a lower strain. It is also believed that the presence of dendritic structures in the cast alloy causes premature fracture. As depicted in Fig. 4b, the dendritic cell forms a wall between the grains, which cannot sustain a higher level of strain, and leads to lower ductility. Ulacia et al. [55] reported that during hot deformation of $\mathrm{Mg}$ based alloys, different DRX may be observed: discontinuous (DDRX), continuous (CDRX), or rotational dynamic recrystallization (RDRX). The DDRX occurs by nucleating new grains and their growth, while CDRX is obtained at the new high-angle boundaries, as a result of local lattice rotations caused by dislocation accumulation [56]. At the same time, the RDRX is acquired near grain boundaries of the new grains, due to increased dislocation density where the intergranular strain incompatibilities occur. However, differentiating between DDRX and RDRX is quite difficult, since both phenomena occurred at the new grains formed during deformation, and both processes cause grain refinement. Thus, it is believed that during forging, DDRX and RDRX occurred simultaneously, which causes the evolution of finer grains along the boundary of the pancaked elongated grains, and reduces the dendritic morphology. The presence of the grain boundaries limits the movement of dislocations. Eventually, improvements in strength and ductility are observed. However, the UTS in the forged condition remains the same, due to incomplete recrystallization. Partiallyrecrystallized grains after forging have been reported in research on the effects of multi-axial forging on as-cast ZK60 Mg alloy [33], where the microstructure of ZK60 was analyzed after 
accomplishing three passes of multi-axial forging, and the grains and intermetallic particles were elongated vertical to the final compression loading.

The tensile-compression asymmetry of the Mg-based alloy is a very common phenomenon. In this study, it is worth noting that the forged alloy possesses a tensile-compression asymmetry (see Fig. 14). The asymmetric behavior can be quantified by the following equation:

$$
\text { Asymmetry level }=\frac{\text { YST }- \text { YSC }}{\text { YST }} \times 100
$$

Then, the magnitude of tension-compression asymmetry for the forged and as-cast materials will be approximately $28 \%$ and $19 \%$, respectively. In the case of forged material, this tensioncompression asymmetry is attributed to the formation of a strong basal texture in the forged materials and the polar nature of twinning, i.e., activation of twinning rotated the c-axis about $86.3^{\circ}$ to the loading axis [56]. When the compression load is exerted perpendicular to the $c$-axis, tension-twinning $\{10 \overline{1} 1\}\langle 10 \overline{1} 2\rangle$ is active; however, when the load is in tension, strain hardening in not prevailed by the twin formation. Tension-compression asymmetry is therefore conspicuous in the material's behavior. Furthermore, a discernible tension-compression asymmetry is evident for as-cast ZK60 though its random texture. The asymmetry stems from different slip and twin behavior in tension and compression. The tension-twins are nucleated during the tension test, while compression loading is mostly dominated by the twin growth, and twin initiation occurs to a significant extent at the onset of the test [57,58]. Vinogradov et al. [59] investigated the asymmetric behavior for as-cast ZK60 and reported that more grains are orientated favorably for tension-twinning in compression than in tension. This is in agreement with the results shown in Fig. 14, where a weak sigmoidal shape is visible in the as-cast tension curve.

Fig. 15 represents strain hardening variation with regards to the strain after yielding point. As seen in the Fig. 15, except for the case of compression loading in the forged sample tested along 
the FD, the strain hardening rate decreases with an increase in strain value. However, when compression loading is applied to the forged sample along LD/RD, the curve consists of 3 stages. First, a rapid decrease occurs, followed by an increase at a strain of $\sim 0.05$. This point is ascribed to the inflection point, attesting that twinning deformation is occurring. Stage B terminates at a strain value of $\sim 0.08$ where again strain hardening rate is decreasing until fracture occurs. A similar trend has also been reported in AM30 extruded Mg alloy [51].

Lastly, as illustrated in Fig. 12b and c and explained earlier, after forging, the $c$-axes are mainly oriented along the FD, while a random orientation was identified in the as-cast materials. It has been reported that DRX can change the crystal orientation, especially the hcp crystal, which is very prone to texture formation [60,61]. This process can occur be (1) nucleation oriented, or (2) growth oriented. In the former, the majority of new grains are nucleated in the dominant final texture orientation, while in the latter, the growth frequency of grains grown in one direction is higher than that of those grown in random directions [61]. In this study, a nucleation oriented texture was observed, due to both DDRX and RDRX, so the maximum sharpness of texture did not increase significantly. Moreover, according to Doherty et al. [62], precipitation and second phase particles can inhibit texture revolution by pinning the grain boundaries. As a matter of fact, in the case of $\mathrm{ZK} 60 \mathrm{Mg}$ alloys, $\mathrm{MgZn} \mathrm{n}_{2}$ and $\mathrm{Zn} \mathrm{Z}_{2} \mathrm{Z}$ are reported to be the key precipitate phases that significantly influence the alloy's behaviour $[63,64]$.

\section{Conclusions}

In the present study, the as-cast ZK60 Mg alloy was forged at elevated temperatures for manufacturing structural parts. From the above results and discussion, the following conclusions can be made: 
(1) Microstructural analysis revealed that bimodal refined grains with a significant reduction of casting defects were formed during forging. However, the dendritic morphologies still existed after the forging process, demonstrating that completed DRX did not occur.

(2) Texture analysis revealed a random texture for the cast material; however, in the case of forged ZK60, grains are orientated toward the FD. As a result, monotonic compression loading showed both tension-compression asymmetry and anisotropic behavior for the forged ZK60.

(3) The yield strength and ductility of the forged ZK60 Mg alloy tested in tension loading increased significantly, while the tensile strength remains about the same. At the same time, the yield strength and ultimate strength in compression increased at the expense of a small decrease in fracture strain.

(4) Fracture analysis showed brittle fracture behavior of the as-cast ZK60, while a ductile fracture surface with some dimples and tear ridges were obvious on the fracture surface of the forged samples. This indicates that more plastic deformation is occurring during the test on the forged sample, meaning that material is more ductile.

\section{Acknowledgement}

This work is financially supported by the Natural Sciences and Engineering Research Council of Canada, the Automotive Partnership Canada (APC) program under APCPJ 459269-13 grant with contributions from Multimatic Technical Centre, Ford Motor Company, and Centerline Windsor. The authors would also like to thank Jonathan McKinley and Lucian Blaga of CanmetMATERIALS for performing the forging trials and Dr. Y. Ding of the University of Waterloo for assistance with SEM and OM. 


\section{References}

[1] B.L. Mordike, T. Ebert, Mater. Sci. Eng. A 302 (2001) 37-45.

[2] Z.A. Luo, G.M. Xie, Z.Y. Ma, G.L. Wang, G.D. Wang, J. Mater. Sci. Technol. 29 (2013) $1116-1122$.

[3] M. Kaseem, B.K. Chung, H.W. Yang, K. Hamad, Y.G. Ko, J. Mater. Sci. Technol. 31 (2015) 498-503.

[4] M.R. Barnett, M.D. Nave, C.J. Bettles, Mater. Sci. Eng. A 386 (2004) 205-211.

[5] J. Xu, B. Guan, H. Yu, X. Cao, Y. Xin, Q. Liu, J. Mater. Sci. Technol, 32 (2016) 1239-1244.

[6] D. Sarker, J. Friedman, D.L. Chen, J. Mater. Sci. Technol. 31 (2015) 264-268.

[7] D. Sarker, J. Friedman, D.L. Chen, J. Mater. Sci. Technol. 30 (2014) 884-887.

[8] F. Pan, M. Yang, X. Chen, J. Mater. Sci. Technol. 32 (2016) 1211-1221.

[9] Y. Estrin, A. Vinogradov, Acta Mater. 61 (2013) 782-817.

[10] R.Z. Valiev, Y. Estrin, Z. Horita, T.G. Langdon, M.J. Zehetbauer, Y. Zhu, JOM 68 (2016) $1216-1226$.

[11] J. Lin, X. Wang, W. Ren, X. Yang, Q. Wang, J. Mater. Sci. Technol. 32 (2016) 783-789.

[12] H. Somekawa, A. Singh, T. Mukai, J. Mater. Res. 22 (2007) 965-973.

[13] J. Albinmousa, H. Jahed, S. Lambert, Int. J. Fatigue 33 (2011) 1127-1139.

[14] A.A. Roostaei , H. Jahed, Mater. Sci. Eng. A 670 (2016) 26-40.

[15] Y. Xiong, Y. Jiang, Int. J. Fatigue 64 (2014) 74-83.

[16] X. Chen, F. Pan, J. Mao, J. Wang, D. Zhang, A. Tang, J. Peng, Mater. Des. 32 (2011) 15261530.

[17] S. Dong, Y. Jiang, J. Dong, F. Wang, W. Ding, Mater. Sci. Eng. A 615 (2014) 262-272.

[18] W.C. Liu, J. Dong, P. Zhang, Z.Y. Yao, C.Q. Zhai, W.J. Ding, J. Mater. Sci. 44 (2009) 2916-2924.

[19] R. Jahadi, M. Sedighi, H. Jahed, Mater. Sci. Eng. A 593 (2014) 178-184.

[20] D.L. Yin, H.L. Cui, J. Qiao, J.F. Zhang, Mater. Res. Innov. 19 (2015) 28-31.

[21] M. Madaj, M. Greger, V. Karas, Mater. Technol. 49 (2015) 267-273.

[22] A. Gryguc, S.K. Shaha, H. Jahed, M. Wells, B. Williams, J. McKinley, Fract. Struct. Integr. 38 (2016) 251-258.

[23] A. Gryguc, H. Jahed, B. Williams, J. Mckinley, Mater. Sci. Forum 828-829 (2015) 291297. 
[24] F. Novy, M. Janecek, V. korik, J. Muller, L. Wagner, Int. J. Mater. Res. 100 (2009) 288291.

[25] Y. Snir, G. Ben-Hamu, D. Eliezer, E. Abramov, J. Alloys Compd. 528 (2012) 84-90.

[26] C. Bettles, M. Gibson, JOM 57 (2005) 46-49.

[27] J.D. Robson, C. Paa-Rai, Acta Mater. 95 (2015) 10-19.

[28] Y. Yuan, A. Ma, X.F. Gou, J. Jiang, F. Lu, D. Song, Y. Zhu, Mater. Sci. Eng. A 630 (2015) 45-50.

[29] W.Z. Chen, W.C. Zhang, L.X. Zhang, E.D. Wang, J. Alloys Compd. 646 (2015) 195-203.

[30] Y.H. Kim, H.T. Sohn, W.J. Kim, Mater. Sci. Eng. A 597 (2014) 157-163.

[31] S.R. Agnew, P. Mehrotra, T.M. Lillo, G.M. Stoica, P.K. Liaw, Acta Mater. 53 (2005) 31353146.

[32] Y.Z. Wu, H.G. Yan, J.H. Chen, S.Q. Zhu, B. Su, P.L. Zeng, Mater. Sci. Eng. A 29 (2013) 54-59.

[33] J.Q. Tao, Y.S. Cheng, S.D. Huang, F.F. Peng, W.X. Yang, M.Q. Lu, Z.M. Zhang, X. Jin, Trans. Nonferrous Met. Soc. China 22 (2012) 428-434.

[34] D.R. Nugmanov, O.S. Sitdikov, M.V Markushev, IOP Conf. Ser. Mater. Sci. Eng. 82 (2015) $1-4$.

[35] E. Vasilev, M. Linderov, D. Nugmanov, O. Sitdikov, M. Markushev, A. Vinogradov, Metals (Basel) 5 (2015) 2316-2327.

[36] P. Moldovan, G. Popescu, D. Bojin, D. Constantinescu, M. Pana, Metall. Int. 14 (2009) 2326.

[37] F. Fereshteh-Saniee, N. Fakhar, F. Karami, R. Mahmudi, Mater. Sci. Eng. A 673 (2016) $450-457$.

[38] N. Ogawa, M. Shiomi, K. Osakada, Int. J. Mach. Tools Manuf. 42 (2002) 607-614.

[39] R. Matsumoto, K. Osakada, Mater. Trans. 45 (2004) 2838-2844.

[40] R. Matsumoto, K. Osakada, CIRP Ann. Technol. 51 (2002) 223-226.

[41] Y. Kwon, Y. Lee, S. Kim, J. Lee, Int. J. Mod. Phys. B 22 (2008) 6064-6069.

[42] G. Kurz, B. Clauw, W.H. Sillekens, D. Letzig, P., Die forging of the alloys AZ80 and ZK60, Manufacturing, Conference: Magnesium Technology Symposium 2009 Location: San Francisco, CA, Date: FEB 15-19, 2009, Magnes. Technol. 2009, Book Series: Magnesium Technology Series, 197-202, TMS, 2009. 
[43] W. Yu, Z. Liu, H. He, N. Cheng, X. Li, Mater. Sci. Eng. A 478 (2008) 101-107.

[44] A. Hadadzadeh, S.K. Shaha, M.A. Wells, H. Jahed, B.W. Williams, Recrystallization behavior and texture evolution during hot deformation of extruded ZK60 magnesium alloy, Conference: Materials Science and Technology 2016, MS\&T 2016, Location Salt Lake City, UT, USA, Date: Oct 23-27, 2016, 281-288, 2016.

[45] H. Watanabe, K. Moriwaki, T. Mukai, T. Ohsuna, K. Hiraga, K. Higashi, Mater. Trans. 44 (2003) 775-781.

[46] C.Y. Wang, X.J. Wang, H. Chang, K. Wu, M.Y. Zheng, Mater. Sci. Eng. A 464 (2007) 5258.

[47] Y. Wu, H. Yan, S. Zhu, J. Chen, A. Liu, X. Liu, Trans. Nonferrous Met. Soc. China 24 (2014) 930-939.

[48] H. Chen, S.B. Kang, H. Yu, J. Cho, H.W. Kim, G. Min, J. Alloys Compd. 476 (2009) 324328.

[49] Y. Xiong, Q. Yu, Y. Jiang, Int. J. Plast. 53 (2014) 107-124.

[50] Q. Yu, J. Zhang, Y. Jiang, Q. Li, Int. J. Fatigue 36 (2012) 47-58.

[51] D. Sarker, D. L. Chen, Mater. Sci. Eng. A 596 (2014) 134-144.

[52] S.K. Shaha, F. Czerwinski, W. Kasprzak, D.L. Chen, Mater. Des. 59 (2014) 352-358.

[53] X. Li, S.M. Xiong, Z. Guo, J. Mater. Sci. Technol. 32 (2016) 54-61.

[54] S.D. Wang, D.K. Xu, B.J. Wang, E.H. Han, C. Dong, Sci. Rep., 6 (2016) 23955.

[55] I. Ulacia, S. Yi, M.T. Pérez-Prado, N.V. Dudamell, F. Gálvez,D. Letzig, I. Hurtado, in: Proc. 4th Int. Conf. High Speed Form, Columbus, Ohio, U.S., March 9-10, 2010.

[56] G. Proust, C.N. Tomé, A. Jain, S.R. Agnew, Int. J. Plast. 25 (2009) 861-880.

[57] Č. Jan, K. Máthis, B. Clausen, J. Stráská, P. Luká, Mater. Sci. Eng. A 602 (2014) 25-32.

[58] K. Máthis, P. Beran, J. Čapek, P. Lukáš, J. Phys. Conf. Ser. 340 (2012) 12096.

[59] A. Vinogradov, D. Orlov, A. Danyuk, Y. Estrin, Mater. Sci. Eng. A 621 (2015) 243-251.

[60] T. Al-Samman, G. Gottstein, Mater. Sci. Eng. A 490 (2008) 411-420.

[61] R.D. Doherty, Prog. Mater. Sci. 42 (1197) 39-58.

[62] R.D. Doherty, D.A. Hughes, F.J. Humphreys, J.J. Jonas, D.J. Jensen, M.E. Kassner, W.E. King, T.R. McNelley, H.J. McQueen, A.D. Rollett, Mater. Sci. Eng. A 238 (1997) 219-274.

[63] G.M. Xie, Z.Y. Ma, L. Geng, Mater. Sci. Eng. A 486 (2008) 49-55. 
[64] X. Chen, X. Huang, F. Pan, A. Tang, J. Wang, D. Zhang, Trans. Nonferrous Met. Soc. China 21 (2011) 754-760.

\section{Table Captions}

Table 1 Chemical composition of as-cast ZK60 Mg alloy (wt\%)

\begin{tabular}{|c|c|c|c|c|}
\hline Element & $\mathrm{Zn}$ & $\mathrm{Zr}$ & Others & $\mathrm{Mg}$ \\
\hline Composition & 5.8 & 0.61 & $<0.30$ & Balance \\
\hline
\end{tabular}

Table 2 Tension monotonic mechanical properties of as-cast and forged ZK60 Mg alloy along different directions

\begin{tabular}{|c|c|c|c|c|}
\hline & & YST (MPa) & UTS (MPa) & $\begin{array}{c}\text { Fracture strain } \\
(\%)\end{array}$ \\
\hline \multirow{2}{*}{ As-Cast } & LD & $138 \pm 0$ & $279 \pm 3$ & $15 \pm 1$ \\
\cline { 2 - 5 } & RD & $140 \pm 1$ & $278 \pm 7$ & $14 \pm 4$ \\
\hline \multirow{2}{*}{ Forged } & LD & $163 \pm 10$ & $286 \pm 4$ & $26 \pm 3$ \\
\cline { 2 - 5 } & RD & $177 \pm 0$ & $284 \pm 1$ & $24 \pm 0$ \\
\hline \multirow{3}{*}{ Extruded [37] } & ED & 267 & 331 & 24.5 \\
\cline { 2 - 5 } & ED & 174 & 326 & 24 \\
\cline { 2 - 5 } & TD & 221 & 316 & 11 \\
\hline Upsetting of cast [37] & - & 224 & 286 & 21 \\
\hline \multirow{2}{*}{ Upsetting of extruded [37] } & ED & 168 & 319 & 32 \\
\cline { 2 - 5 } & TD & 198 & 290 & 13 \\
\hline
\end{tabular}

Table 3 Monotonic mechanical properties under compression of as-cast and forged ZK60 Mg alloy

\begin{tabular}{|c|c|c|c|c|}
\hline & & YSC $(\mathrm{MPa})$ & UCS $(\mathrm{MPa})$ & $\begin{array}{c}\text { Fracture Strain } \\
{[\%]}\end{array}$ \\
\hline \multirow{2}{*}{ As-Cast } & LD & $109 \pm 6$ & $352 \pm 4$ & $19 \pm 0$ \\
\cline { 2 - 5 } & RD & $118 \pm 0$ & $354 \pm 4$ & $19 \pm 1$ \\
\hline Forged & LD & $111 \pm 1$ & $390 \pm 6$ & $13 \pm 1$ \\
\hline
\end{tabular}




\begin{tabular}{|c|c|c|c|c|}
\hline & RD & $119 \pm 1$ & $391 \pm 4$ & $14 \pm 1$ \\
\cline { 2 - 5 } & FD & $127 \pm 4$ & $373 \pm 13$ & $15 \pm 0$ \\
\hline
\end{tabular}

Table 4 Geometry for the tension dog-bone sample

\begin{tabular}{|l|l|l|l|}
\hline$x(\mathrm{~mm})$ & $y(\mathrm{~mm})$ & $\mathrm{x}(\mathrm{mm})$ & $y(\mathrm{~mm})$ \\
\hline 0.00 & 3.00 & 7.64 & 3.37 \\
\hline 0.68 & 3.00 & 8.38 & 3.49 \\
\hline 1.37 & 3.00 & 9.14 & 3.63 \\
\hline 2.05 & 3.01 & 9.93 & 3.82 \\
\hline 2.74 & 3.03 & 10.69 & 4.05 \\
\hline 3.42 & 3.04 & 11.36 & 4.37 \\
\hline 4.11 & 3.07 & 11.77 & 4.71 \\
\hline 4.80 & 3.11 & 12.01 & 4.98 \\
\hline 5.50 & 3.15 & 12.25 & 5.34 \\
\hline 6.20 & 3.20 & 12.52 & 6.00 \\
\hline 6.91 & 3.28 & 40.00 & 6.00 \\
\hline
\end{tabular}

\section{Figure Captions}

Fig. 1 Geometries of ZK60 Mg alloy after forging at (a) $350^{\circ} \mathrm{C}$ and (b) $450^{\circ} \mathrm{C}$ (Note that lowering the deformation temperatures causes severe edge cracks in the materials as seen in (a)).

Fig. 2. Schematic of specimen locations and direction convention for (a) as-cast and (b) forged ZK60 Mg alloy.

Fig. 3. Typical specimen geometries for (a) compression and (b) tension tests (All dimensions are in millimeters $(\mathrm{mm})$ except the surface roughness, which is 0.2 micrometers $(\mu \mathrm{m})$; Axes $x$ and $y$ are axes of symmetry) 
Fig. 4. Typical OM (a, b) and SEM (c, d) microstructures of the as-cast ZK60 Mg-alloy in conjunction with EDX (e) line scans exhibiting the presence of intermetallics containing $\mathrm{Zn}$ and $\mathrm{Zr}$. The microstructure was taken in (a, c) unetched and (b, c, d) etched conditions.

Fig. 5 XRD patterns showing the phases present in the ZK60 Mg alloy in as-cast condition. The inserted graph is the magnified view of the $y$-axis.

Fig. 6. Typical OM microstructures of as-cast followed by forging ZK60 Mg-alloy in (a) unetched and $(b, c)$ etched conditions. The location enclosed by yellow box is the magnified view illustrated in (c).

Fig. 7. PF of (0002) and (10 $\overline{1} 0)$ obtained from ZK60 Mg alloy in (a) as-cast and (b) forged condition. The schematic illustration shows the orientation of the hcp unit cell in the material.

Fig. 8. Typical engineering stress-engineering strain curves under tension loading of ZK60 Mgalloy in as-cast and forged conditions tested at LD and RD and a strain rate of $10^{-3} \mathrm{~s}^{-1}$.

Fig. 9. Typical engineering stress-engineering strain curves under compression loading of ZK60 $\mathrm{Mg}$ alloy in as-cast and forged conditions tested at LD, FD, and RD and a strain rate of $10^{-3} \mathrm{~s}^{-1}$.

Fig. 10. Typical engineering stress vs. engineering plastic strain curves under monotonic compression loading in as-cast and forged ZK60 Mg alloy.

Fig. 11. Polished cross-sectional morphologies showing fracture face profile with basal (0002) pole figures of (a) as-cast and (b) forged ZK60 Mg alloy after tension testing. The enclosed yellow line shows the secondary crack near the fracture surface in the cast materials. 
Fig. 12. Polished cross-section morphologies showing microstructures near fracture surface with basal (0002) pole figures after compression testing for (a) as-cast and forged ZK60 Mg alloy followed by compression along (b) LD and (c) FD. The enclosed yellow boxes show the location of higher magnified images. Note that the schematic shows the orientation of the unit cells in the grains before and after deformation.

Fig. 13. SEM micrographs showing overall and magnified view of tensile fracture surface of ZK60 Mg-alloy in (a, b) as-cast and (c, d) forging conditions at (a, c) low and (b, d) magnification.

Fig. 14. Typical engineering stress-engineering strain curves under tension and compression loading of ZK60 Mg alloy in as-cast and forged conditions exhibiting asymmetric behavior in both conditions.

Fig. 15. Typical strain hardening rate-engineering strain curves under tension and compression loading of ZK60 Mg alloy in as-cast and forged conditions.
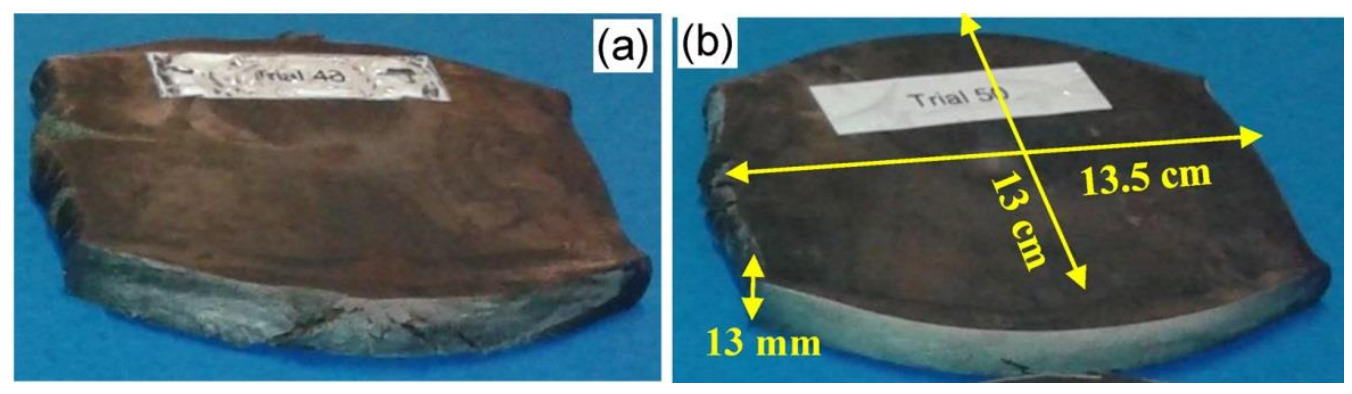

Fig.1 
(a)

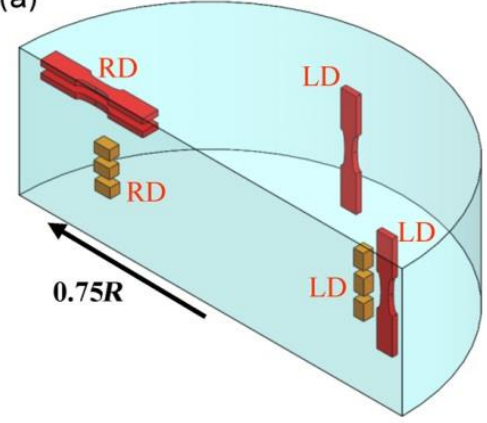

(b)

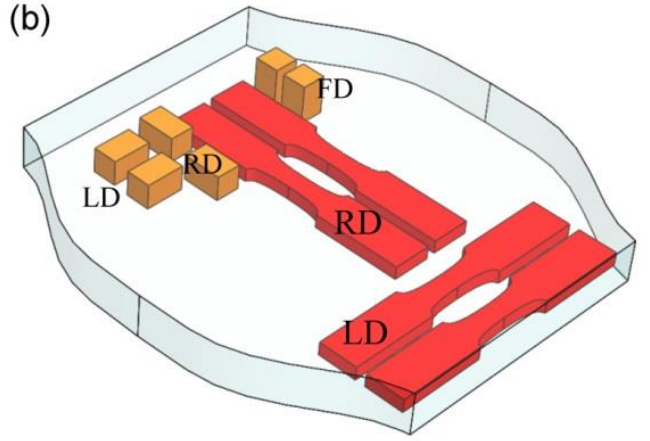

Fig.2

(a)

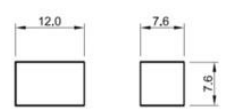

(b)

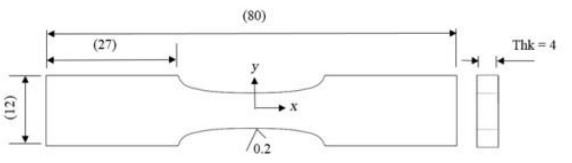

Fig. 3 

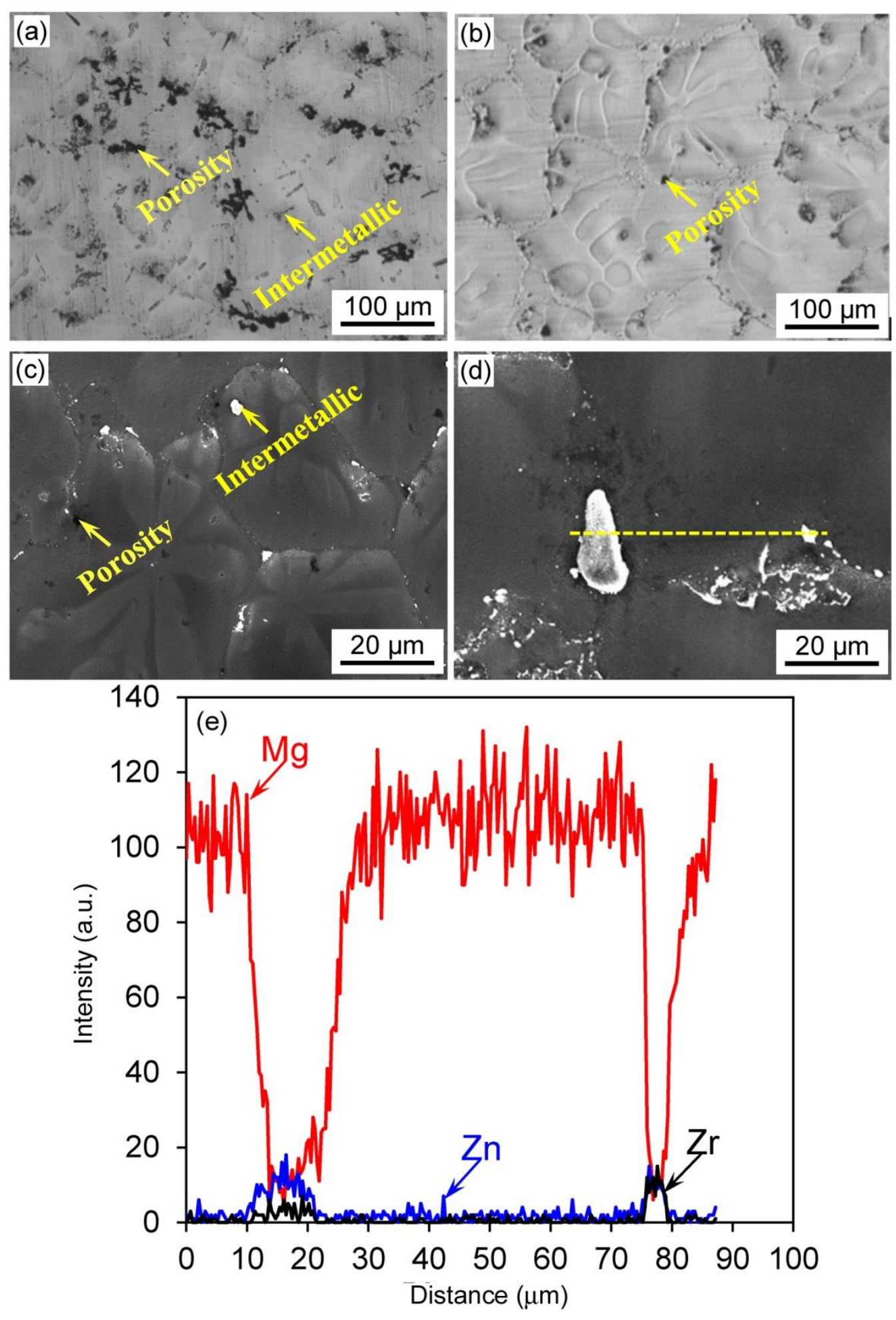

Fig.4 


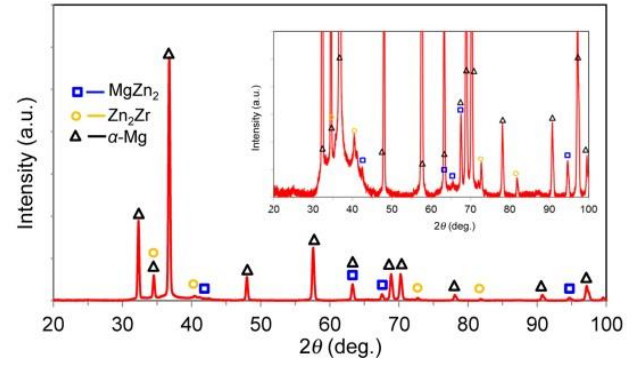

Fig.5

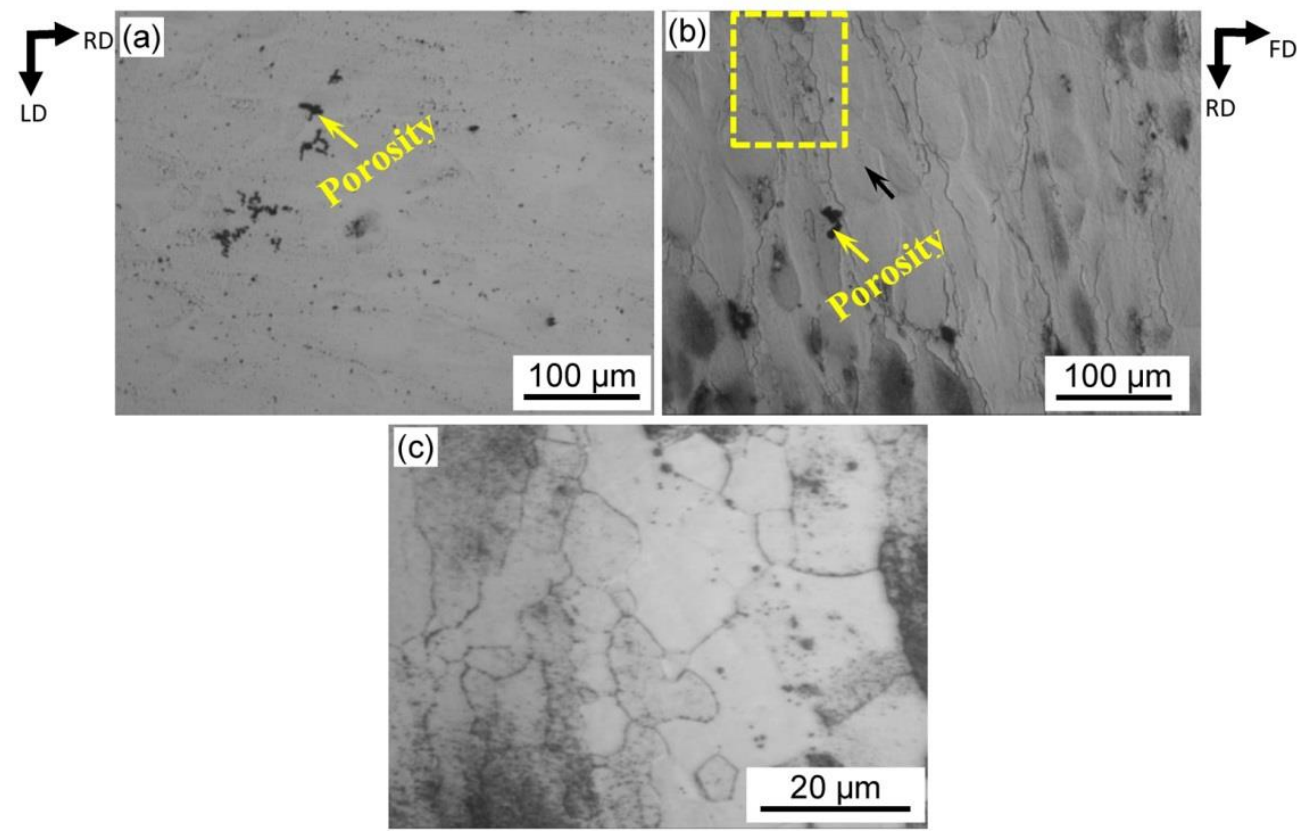

Fig.6 


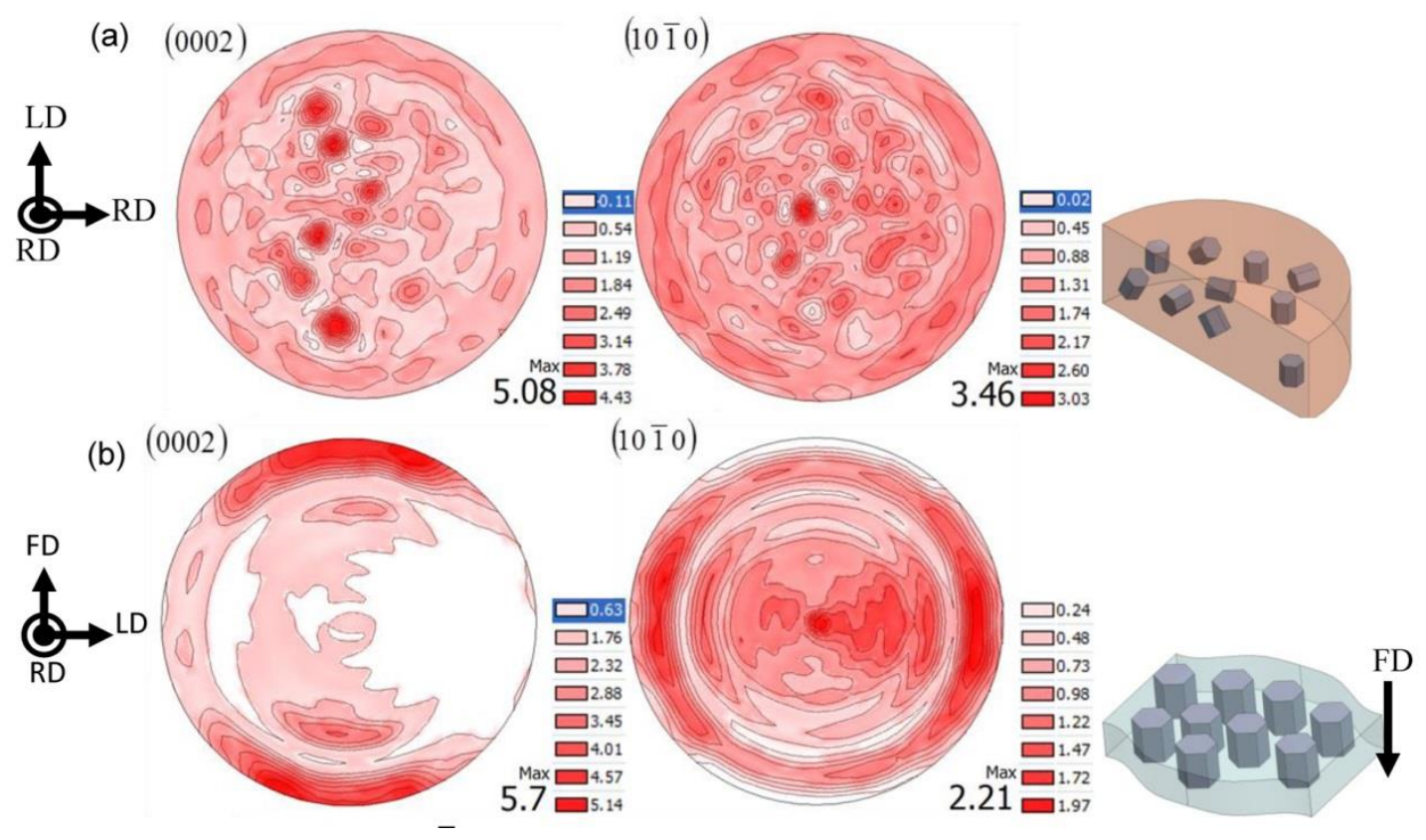

Fig.7

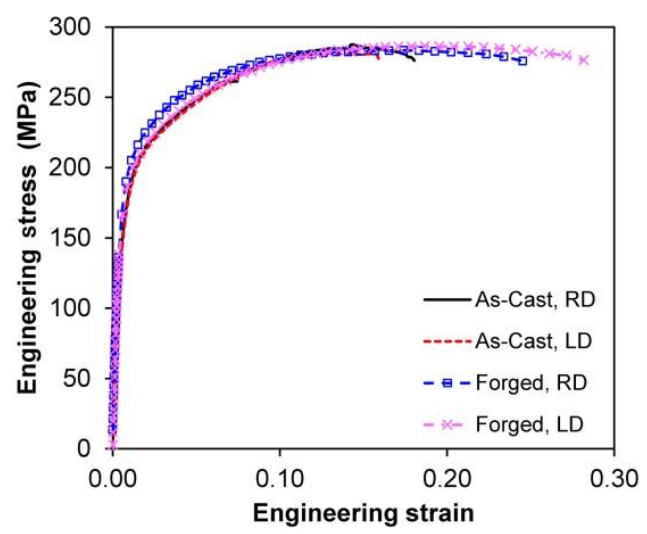

Fig.8 


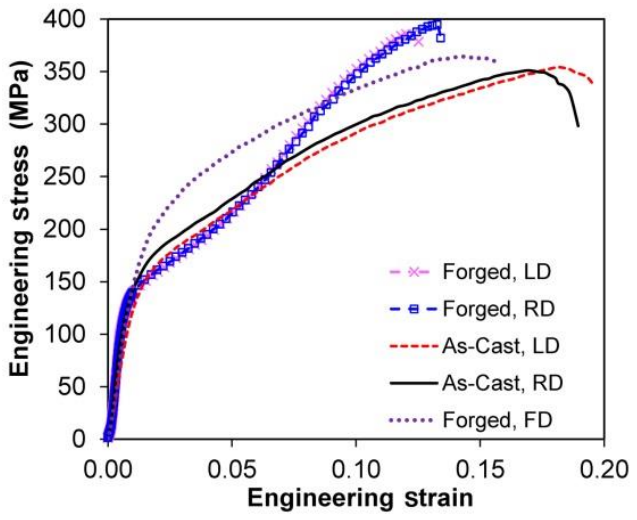

Fig.9

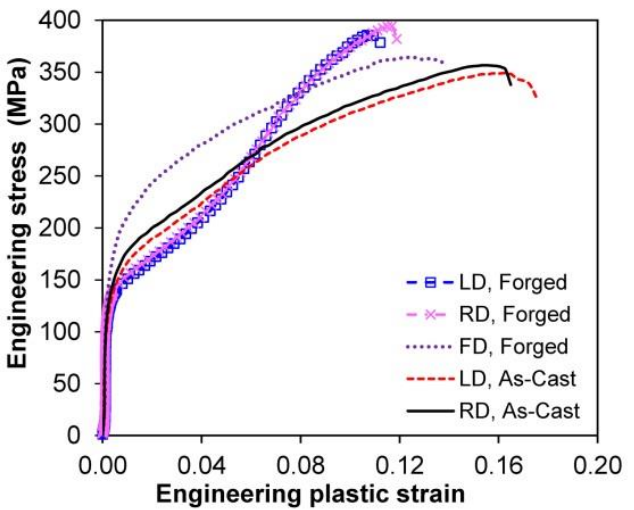

Fig.10 

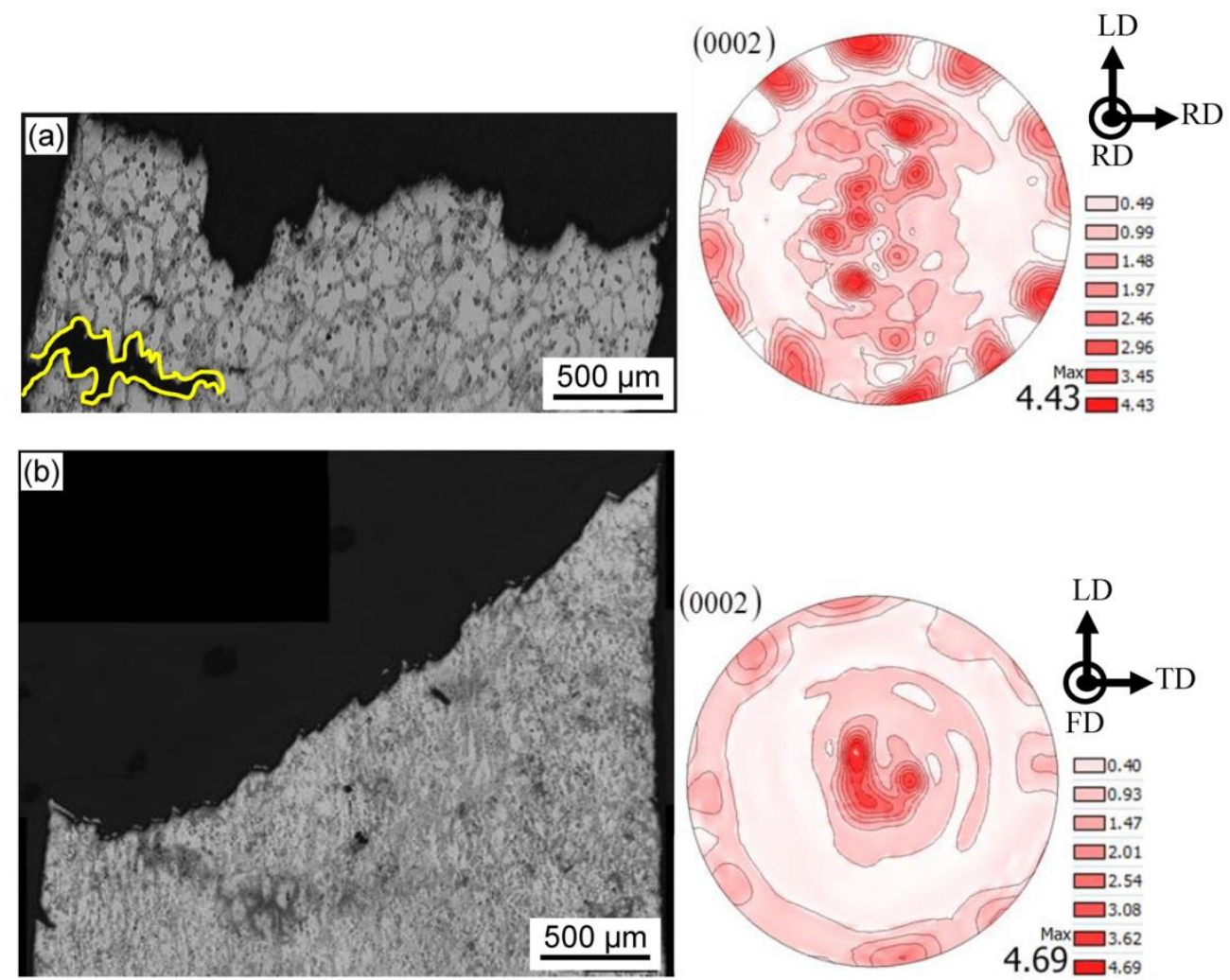

Fig.11 

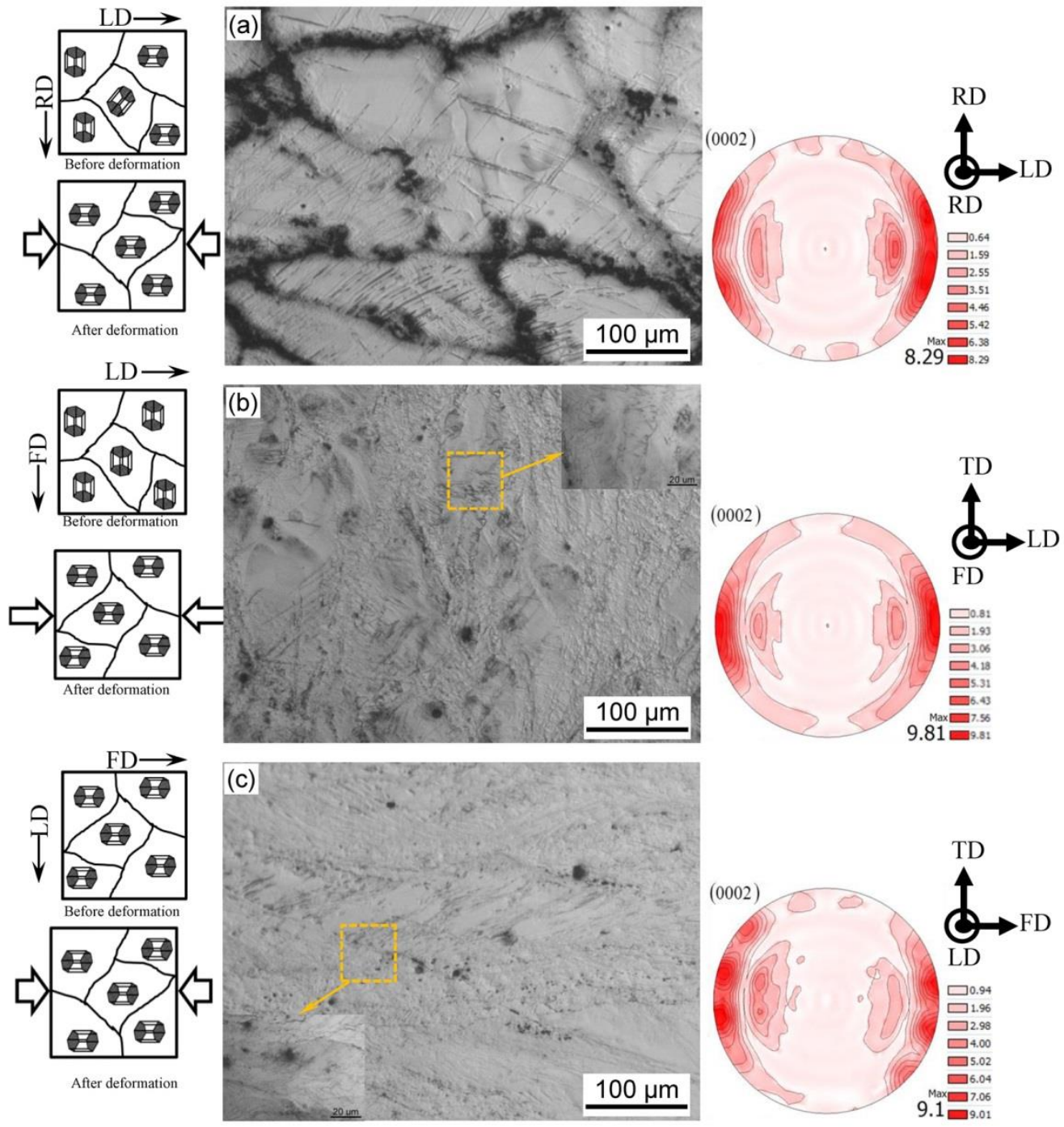

Fig. 12 

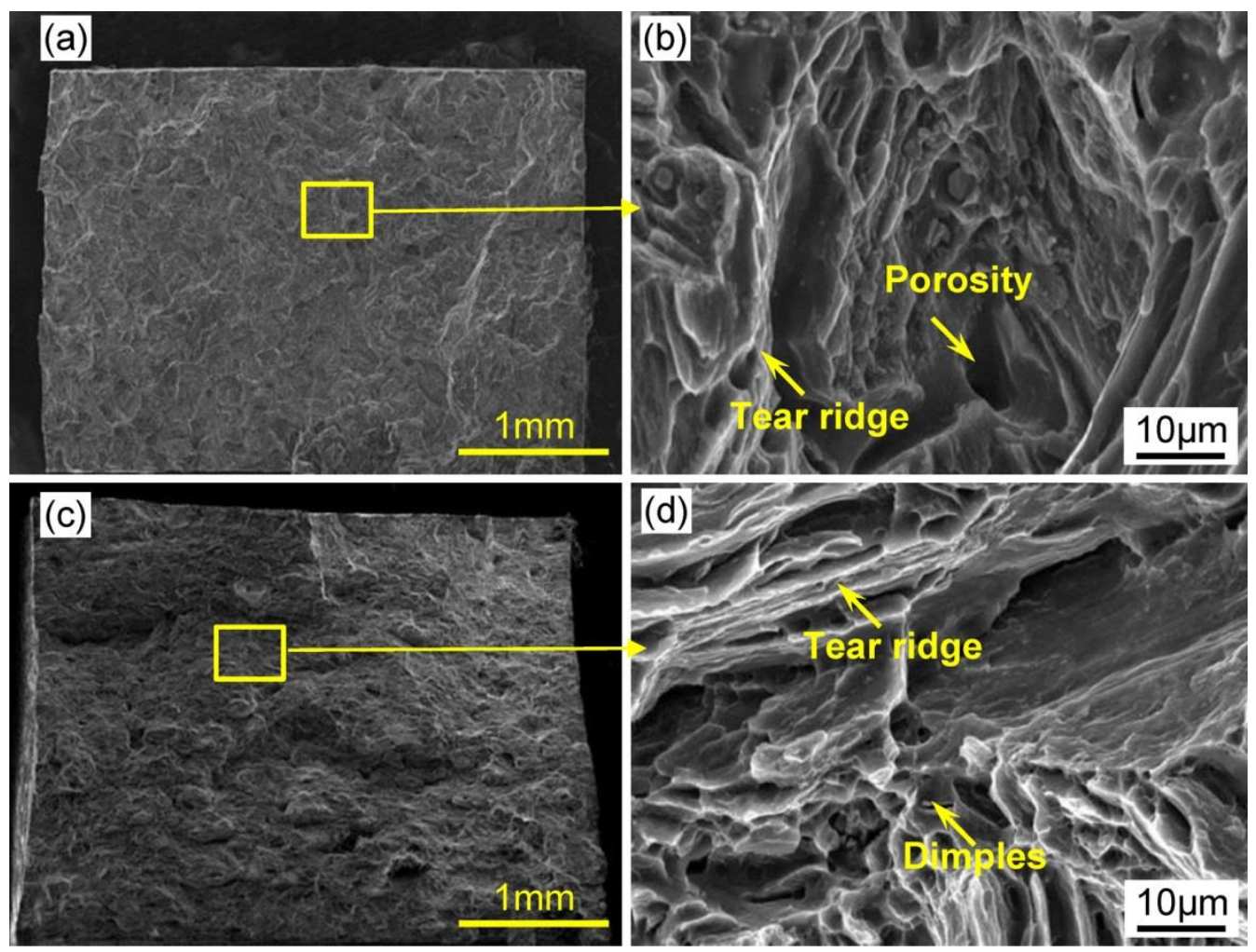

Fig. 13

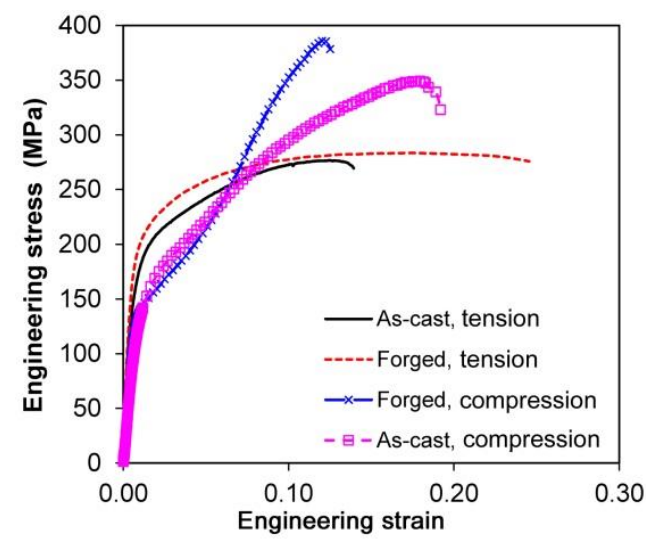

Fig. 14 


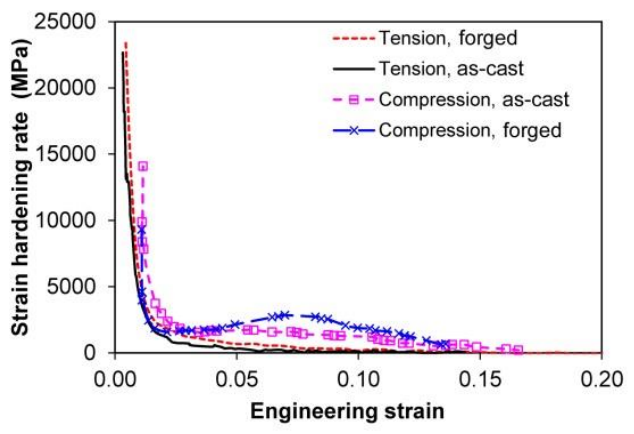

Fig. 15 